\title{
Humanizing the hospital: Design lessons from a Finnish sanatorium
}

This article was posted at cmaj.ca on Sept.21, 2009.

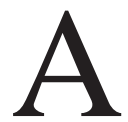

s medicine has moved toward evidence-based practice, so too has hospital design, which is increasingly guided by research linking physical environments to health care outcomes through the process of evidence-based design. ${ }^{1}$ There is evidence that well-designed physical settings play an important role in making hospitals safer while promoting the healing of patients.

In the past, only modest attention was given to providing surroundings that calmed patients and addressed their emotional needs. In recent years, research has shown that conventional hospital designs can heighten stress, diminish satisfaction with care, reduce safety, worsen medical outcomes, diminish staff morale and decrease overall effectiveness in delivering care. Additional research supports the view that the improved design of hospital environments can play a role in reducing stress, making patients safer, promoting better outcomes and enabling staff to do their jobs more effectively and with less strain. ${ }^{1}$

The term "evidence-based design," officially defined in 2003 by health care architect D. Kirk Hamilton, has evolved as it has been applied. ${ }^{2}$ The Center for Health Design now defines evidence-based design as "the process of basing decisions about the built environment on credible research to achieve the best possible outcomes." Although evidence-based design is a recent concept, historic examples demonstrating an awareness of the benefits of psychologically supportive spaces no doubt played an important role in the development of this design model.

Florence Nightingale's observations

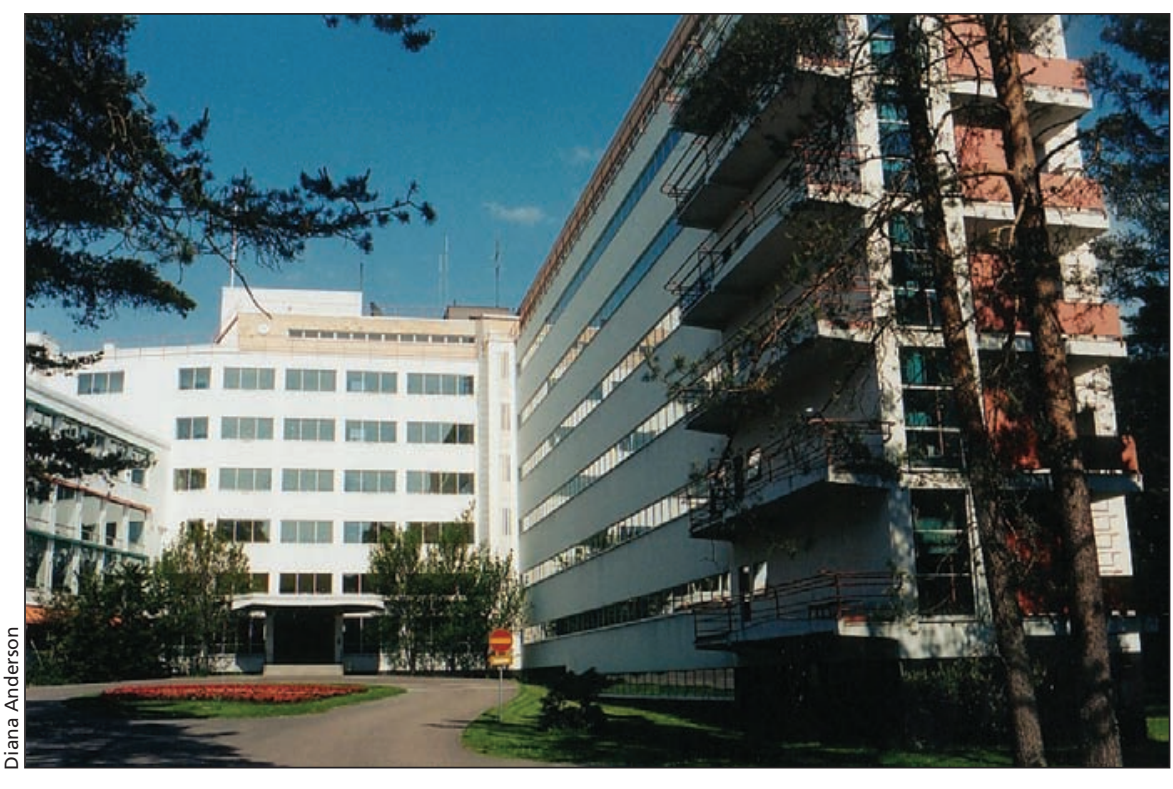

The Paimio Sanatorium in Finland, designed by Alvar Aalto, has been nominated as a UNESCO World Heritage Site.

after her experiences tending to wounded soldiers during the Crimean War of 1853 illustrate an early appreciation of the importance of hospital space design. ${ }^{4}$ Nightingale noted in her diary in 1860: "I mention from experience, as quite perceptible in promoting recovery, the being able to see out of a window, instead of looking against a dead wall; the bright color of flowers, the being able to read in bed by the light of a window close to the bed-head. It is generally said that the effect is upon the mind. Perhaps so, but it is not less so upon the body on that account. ..."

Today it is recognized that high quality design can improve and contribute to patient experiences and outcomes. Many design elements are no longer viewed as optional, but are now seen as fundamental requirements for health care facilities, such as the incorporation of nature and access to natural light. ${ }^{1}$

The Paimio Sanatorium, built in the early 1930s in the southwest portion of Finland, demonstrates an appreciation for good design and the ambition to create healing environments that emulate nature. Visitors will be impressed by the comprehensive design strategies that the architect used when planning the facility over 70 years ago. The hospital, which was originally designed and built for patients with tuberculosis, is carefully sited among pine trees fitting the hospital's functional requirement of isolation. Alvar Aalto, one of the most recognized architects of the 20th century and a native of Finland, was the winner of the 1927 architectural competition to plan the facility (www.alvaraalto.fi /indexe.htm). He designed the sanatorium with not only the patient with tuberculosis in mind, but also as his primary inspiration. ${ }^{6}$

The details incorporated into the building design by Aalto illustrate many of the evidence-based design 


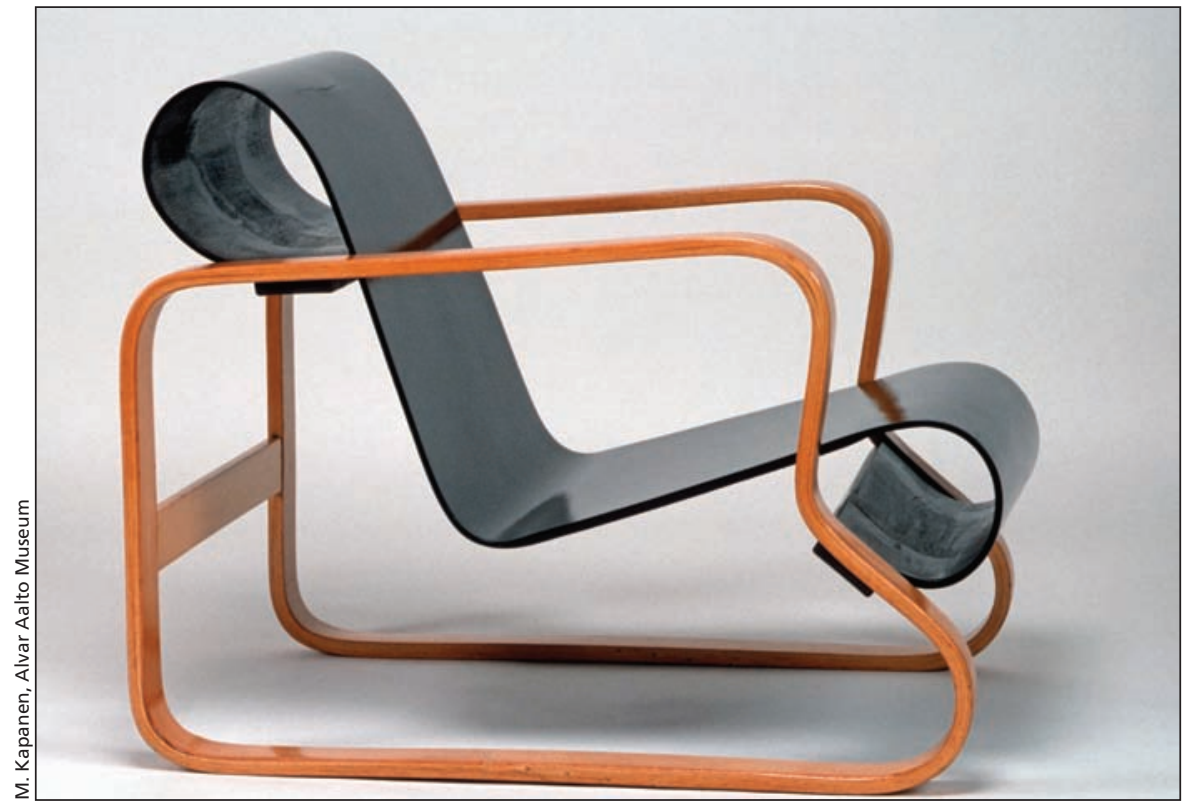

Aalto's Paimio Sanatorium chair, of bent and solid birch, is admired as much for its sculptural quality as for its comfort. It influenced the chairs designed by Charles and Ray Eames.

strategies published in recent years. Patients generally stayed in the sanatorium for long periods where a common treatment method for tuberculosis was daily exposure to the open air, therefore the hospital design had to allow for access to the exterior. To address these aspects of the illness and its treatment, Aalto designed a large roof terrace with extensive views of the forest, allowing sick patients to be taken in their beds up for fresh air as part of their daily routine. He planned winding paths on the hospital grounds and incorporated water features, which encouraged patients to take walks. A sun balcony was added at the end of each patient floor and oriented directly southward, with the intention for bedridden patients on the balconies to get as much natural light as possible. ${ }^{6}$

Each patient room was planned for two people, with the architect keeping in mind the reclining patient as his primary inspiration. For Aalto, a peaceful environment was a prerequisite for the healing process, therefore rooms were designed to be as comfortable and quiet as possible. He believed that each patient should have his own wash basin and designed tilted faucets to prevent noise and splashing. All the patient rooms had full morning suncolour to promote brightness of the space.

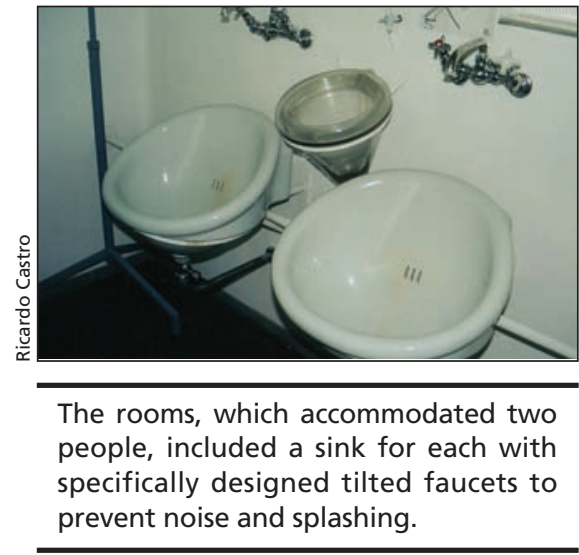

draft proof, and doorknobs were shaped to fit the hand. ${ }^{6}$

Expanding his architectural solutions beyond the physical layout of the building itself, Aalto designed many of the fixtures and furniture to be utilized in the facility. The best-known of the Paimio Sanatorium chairs, the so-called Paimio Chair from 1931, is still produced today. The angle of the chair's back, built from bent birch plywood and therefore easy to clean, was designed to optimize the best position for the seated patient to breathe. ${ }^{6}$

Communal spaces such as dining areas and lounges were planned to face different directions and thus are not all simultaneously in full sunlight, allowing patients to choose either a light or shady sitting area. Large windows at each of

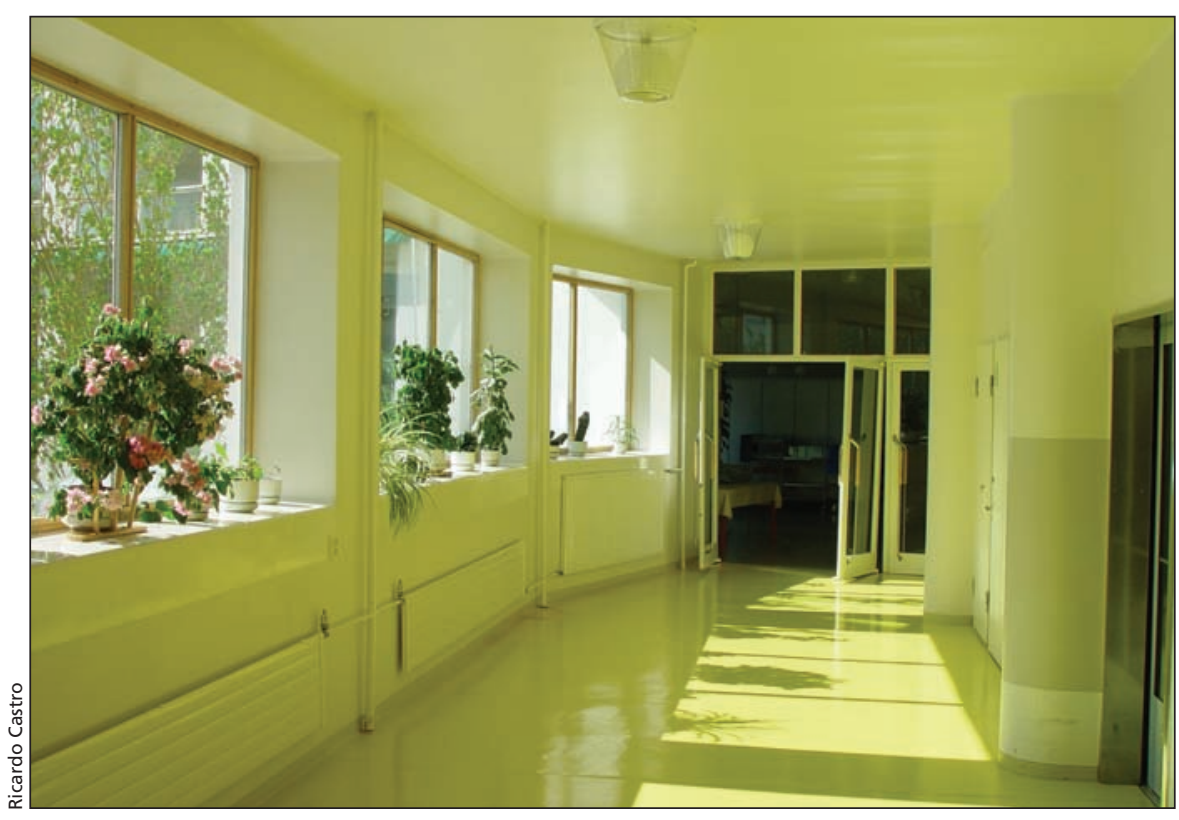

This interior view of the main hospital wing demonstrates the architect's use of interior 


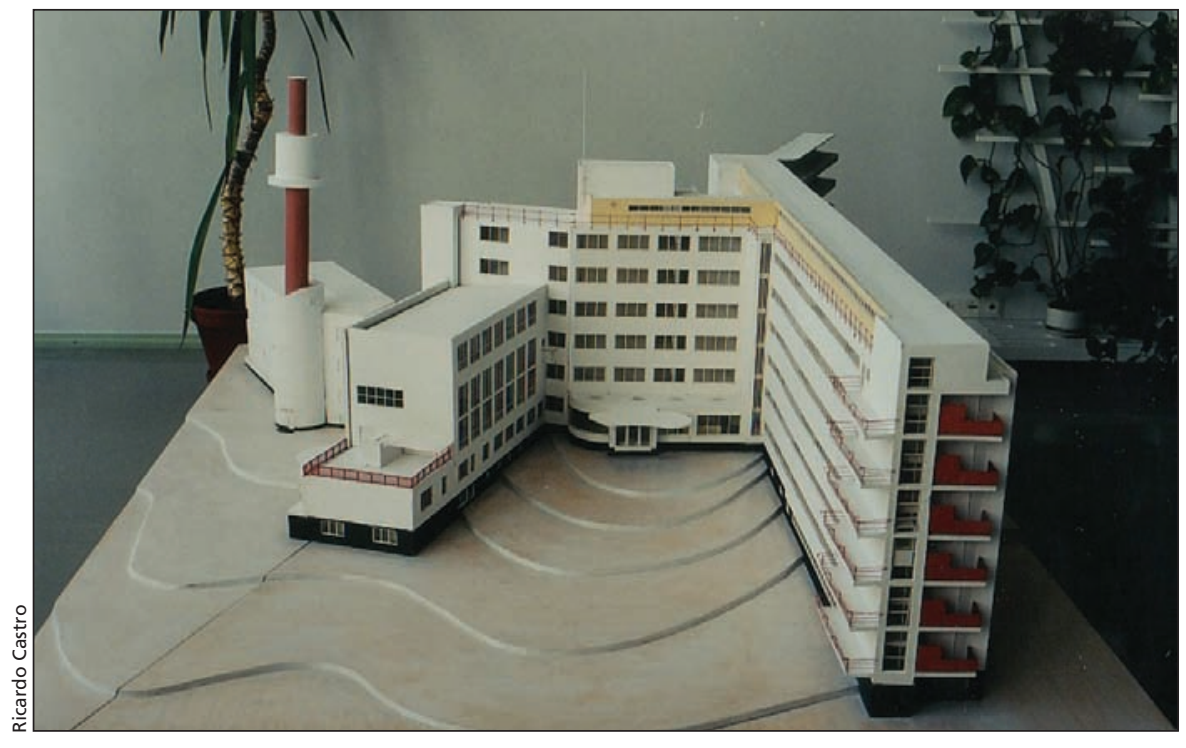

This architectural model of the Paimio Sanatorium shows how the overall floor plan was based on a fan shape where functions were subdivided into separate wings: on the left is the wing containing the communal spaces, on the right is the patient's wing containing south-facing sun balconies. The two wings were connected by a middle section containing the vertical circulation connections.

the landings of the main staircase offer views toward the forest. Through the use of colour, Aalto wanted to create a comfortable and humane atmosphere in the common areas of the hospital. Strong colours were intermittently used, such as yellow rubber flooring in the corridors and stairwell of the central wing, adding to the feeling of brightness and sunlight. Today it is becoming common for architects to hold focus groups or employ registered health professionals to obtain feedback on the design of health care buildings, but in the 1930s, this was not the case. Aalto was ahead of his time in consulting with physicians as he planned the sanatorium. The building board included a physician, and statements from experts were incorporated into the preparation of the drawings. ${ }^{6}$

Prior to the development of evidence-based design, Aalto created a healing environment addressing each patient's psychological and social needs. The Paimio Sanatorium served exclusively as a tuberculosis sanatorium until 1971, when it was converted into a general hospital, still functioning today. In 2005, the building was nominated as a World Heritage Site with the
United Nations Educational, Science and Cultural Organization. ${ }^{6}$ Just as the starting point in Alvar Aalto's design was the individual whose privacy and comfort were of central importance, the current field of evidence-based hospital design emulates this focus of the physical setting as therapeutic.

While the study of evidence-based design is still in its infancy, the amount of credible research is expanding rapidly. This new era of hospital design promises to be a time for fundamental change, promoting ongoing empowerment of the patient and family, along with a continuing emphasis on supportive health care architecture and its contribution to healing.

\section{Diana Anderson MD MArch 2008-2009 Tradewell Fellow WHR Architects, Inc. Houston, USA}

\section{REFERENCES}

1. de Swaan A, Jencks C, Verderber S, et al. In: Wagenaar C, editor. The Architecture of Hospitals. Rotterdam (NL): NAi Publishers; 2006. p. 271-89.

2. Viets E. Lessons from evidence-based medicine: what healthcare designers can learn from the medical field. HERD 2009;2:2.

3. The Center for Health Design Website. Available: www.healthdesign.org/aboutus/mission/EBD _definition.php (accessed 2009 Sept. 10).

4. Strathern P. A Brief History of Medicine from Hippocrates to Gene Therapy. New York (NY): Carroll \& Graf Publishers; 2005. p. 249-71.

5. de Swaan A, Jencks C, Verderber S, et al. In: Wagenaar C, editor. The Architecture of Hospitals. Rotterdam (NL): NAi Publishers; 2006. p. 376.

6. National Board of Antiquities. Nomination of Paimio Hospital for Inclusion in the World Heritage List. Helsinki (Finland): The Board; 2005. Available: www.nba.fi/tiedostot/c760469d.pdf (accessed 2009 Sept. 10). 